\title{
Commentary: In Defense of the Contract at Will
}

\author{
Sherwin Rosen $\dagger$
}

Professor Epstein's paper is very thoughtful and thought-provoking, and is squarely at the center of a great deal of recent economic research on contracts. This research has been one of the most fruitful outcomes of the interaction between law and economics. Someone has said that economists study the devices for and consequences of enforcing contracts, while lawyers specialize in finding imaginative ways in which contracts can be broken. Perhaps in this respect a contract at will is the best of all possible worlds, since it can in a sense be enforced and broken simultaneously.

At a very abstract level, contracts at will differ from other types in that they do not specify a definite duration for the agreement. Rather the contract is open-ended and is broken when either side walks away and thereby terminates it. There are two main economic reasons why contracts at will are desirable. The more obvious arises when the gains from exchange that induce the contract are of uncertain duration and this uncertainty is common knowledge among the participants. This is what Epstein has in mind when he says that both parties "know what they do not know." In an employment contract, the worker may get a superior offer whose value exceeds that of the existing job. These offers tend to come in at random intervals. Similarly, the firm may suffer adverse fortunes that cannot be foreseen, except in terms of probabilities, at the time the exchange is initiated. An exchange is efficient if and only if the gains from the exchange to both parties exceed their opportunity costs (i.e., the gains forsaken in order to complete the exchange). The relationship should be ended when the total gains (to both parties) from continuing the relationship fall short of the total gains from termination. If the point in time at which the gains from the relationship will vanish is foreseeable, then a definite duration can be written into the contract; but when

† Edwin A. and Betty L. Bergman Professor of Economics, University of Chicago.

${ }^{1}$ Epstein, In Defense of the Contract at Will, 51 U. CHI. L. Rzv. 947, 969 (1984) (emphasis in original). 
the appropriate point for termination cannot be foreseen so precisely, the agreement should be open-ended and at-will.

More is at stake here, however, than simple uncertainty. If all probabilistic states were knowable and easily verified, then statecontingent contracts would dominate all other types. Thus the contingent contract specifies termination whenever certain nonadvantageous states occur and specifies continuation otherwise. A contract at will, by contrast, tends to save resources because it does not have to specify all possible contingencies, of which there may be millions. This is an argument involving transaction costs. The efficient contract should allocate resources to their highestvalued uses net of transaction costs. Since by nature contracts cannot be completely state-contingent, some contract terms must be set for random intervals rather than for fixed intervals (and virtually all labor contracts involve elements of both).

An important implication is that at-will contracts are not unilateral. Rather, they are inherently bilateral and have important partnership elements. ${ }^{2}$ For example, the arrival of a better offer for one party signals a need for negotiation and recontracting so that the previous terms can be modified (including possible abandonment of the relationship). These negotiations are always bilateral because, with full information and cooperation, a worker never quits unless the employer wants him to, and a worker is never fired unless it is beneficial to both parties for him to leave. A rational party never unilaterally walks away from an efficient contract. Atwill contracts focus recontracting to those points in time when it is beneficial to recontract, i.e., when the relevant states actually change, and may save resources for this reason.

The second economic reason for the desirability of contracts at will comes from recent research involving repeated games. ${ }^{3}$ Potential legal and other conflicts in an employment relation are of most interest when the nature of the exchange between worker and firm involves some surplus that is specific to the transaction. This is quite different from the standard competitive-market paradigm, where surplus for participating is specific to the market as a whole, rather than to the identities of actual transactors. In the standard paradigm, breaking a contract has little consequence because there is an equivalent party with whom a new contract may be struck-a perfect substitute. When the identity of the traders matters, how-

Cf. id. at 958-62.

'See, e.g., Telser, A Theory of Self-Enforcing Agreements, 53 J. Bus. L. 27, 29-30 (1980). 
ever, transaction-specific rents create a host of noncooperative strategic considerations having to do with the division of rents between the parties.

To illustrate, suppose rents exist and the parties enter into an initial agreement. After the contract has continued for a while, one party may devise threats for the purpose of extracting the other's gains. The theory of repeated games shows how the threat of dissolution can itself lead to a self-enforcing agreement. That the aggrieved party can walk away from the agreement after misbehavior by the other will sometimes serve as a sanction sufficient to deter short-term adventurism of this type. Still, the circumstances under which the threat of walking alone would be a sufficient deterrent are quite severe: the value of the contract to both parties must either be expected to continue indefinitely or have a substantial positive probability of continuing at all future dates, and both parties must be sufficiently farsighted in their sense of subjective time preference. Otherwise there are well-known tendencies toward opportunism as the end-period approaches, and a contract at will is not self-enforcing. ${ }^{4}$

Nevertheless, there is nothing sacred about self-enforcing con-

- See generally Kennan, Bonding and the Enforcement of Labor Contracts, 3 EcoN. LETTRRS 61 (1979). In these usual circumstances, where an end can be foreseen, it is known that a double-bonding scheme reduces incentives for opportunism. See Telser, supra note 3, at 43. For example, suppose the worker and employer have the opportunity to make a specific capital investment that yields a $10 \%$ return and that the market rate of interest is also $10 \%$. Suppose the investment amounts to $\$ 100$. The employer puts $\alpha 100$ into the specific investment and $(1-\alpha) 100$ into an interest-bearing security, while the employee puts $(1-\alpha) 100$ into the specific investment and $\alpha 100$ into the market security. An escrow account is set up for the security, and the contract is at will: if either party walks the other side gets the full $\$ 100$ security. The return structure is set up so that if no one walks away from the contract then each party receives $10 \%$ of the $\$ 100$ sum they put up, which is precisely his opportunity cost. That this is efficient is suggested by the fact that it looks like sole ownership of the specific investment to each party-both are getting, in effect, a $100 \%$ share of the return to the specific asset, and no more than they could get elsewhere. They both face the same marginal incentives, and there is complete harmony of interest.

That this is not necessarily an ideal solution is suggested by several considerations. First, the contract requires an honest third party to hold the bonds. Second, as the day of termination comes near, each party has incentives to take actions and spend resources to induce the other to walk away so he can get the entire security for himself-the firm tends to mistreat the worker to get him to quit, or the worker tends to misbehave to induce the firm to fire him. Third, change the problem a little bit. Suppose the marginal return on the specific investment for the last dollar spent out of the $\$ 100$ is $10 \%$, but that the average return is greater than that, say $15 \%$. Suppose the total return is to be split equally. Then each gets $\$ 12.50$ on his $\$ 100$ investment or $12.5 \%$, which is in excess of the $10 \%$ opportunity cost. The incentive to expropriate the other party's excess $2.5 \%$ return arises again. In short, we possess no satisfactory theory of noncooperative rent-splitting that is compatible with first-best economic efficiency. 
tracts. It may be that in many situations a contract that requires significant monitoring of the actions of both parties is relatively efficient. The concept of efficiency here must net out the costs of monitoring and enforcement from the gross gains from the exchange. These costs include expected litigation costs of enforcing for-cause clauses, among other things. A no-fault at-will contract avoids these monitoring and enforcement costs but may add significant social costs caused by opportunistic behavior. At-will contracts should be observed when the enforcement costs of other non-self-enforcing contracts are sufficiently large in relation to the costs of opportunism associated with at-will contracts. Contracts that are not at-will should be observed in the opposite circumstance. Epstein's defense of at-will labor contracts therefore amounts to arguing that the former set of circumstances dominates labor-market exchange. To justify this he appeals to recent research on principal-agent relationships, as well as to the large costs of formal litigation.

When we come down to cases, an employment contract is a very curious creature, since the nature of the exchange is not made very explicit in most instances. On one hand, employment is an authoritarian relationship in which the employee undertakes an obligation to follow certain orders and commands of the employer. On the other hand, it contains important elements of delegation in which the employee is given latitude within broad limits to behave in the interests of the firm. Some elements of the contract are express or clearly implied and are actionable for breach (e.g., nonpayment for work done or misappropriation of firm property). But most terms of the contract (not merely its duration), are left unspecified, precisely because it is too costly to write them down and to verify that they have been performed. These therefore represent an implicit understanding about which there may be significant scope for disagreements through asymmetrical information.

At-will contracts protect both parties against actions by the other that are beyond the terms of this mutual implicit understanding. It is clear that the courts cannot condone attempts to induce criminal actions (as, for example, in the Petermann case ${ }^{5}$ ). But some of the other cases discussed by Epstein left me far more uneasy. I kept asking myself what the mutual understanding might have been and whether the actions taken were conformable with it. If some monitoring is necessary to achieve efficiency in contracting,

- Petermann v. Teamsters Local 396, 174 Cal. App. 2d 184, 344 P.2d 25 (1959). See Epstein, supra note 1, at 952 \& n.11. 
precisely why is it that these implicit terms should not be actionable, as they are, for example, in commercial law?

A clear example of the use of litigation-type mechanisms for this purpose arises in union contracts, where the at-will rule is not applied. These contracts do not specify a complete list of contingencies. Instead, they specify a defined "grievance procedure" under which various conflicts are handled by arbitration as they arise. And in fact it is probable that most nonunion firms adopt at least informal grievance procedures, just as a matter of good labor relations. Where they do not, self-enforcement of at-will agreements would have to depend on uneasy and slippery notions of "reputations" as bonding equivalents. Much energy is now being devoted by economic theorists to investigating the extent to which reputations suffice to prevent opportunistic behavior in labor-market and other types of exchange, though the general topic is an old one. "My word is my bond" is a meaningful statement in a tightly knit trading community where information travels fast and the value of repeat business is very large compared with the value of breaking an agreement. No doubt these circumstances apply to much labor-market exchange, but it is an empirical question, and still open, of the extent to which they do. In fact, partners occasionally abscond; trusted employees are sometimes caught shirking, embezzling, and selling trade secrets; and more than one firm has been known to terminate employees on the day prior to pension vesting. Are these well-publicized examples so infrequent that when the costs of litigation or arbitration are factored into the picture, the defense of at-will contracts is compelling? The fact that this institution has survived for so long suggests that Epstein is right to give an affirmative answer. But one might rest easier with some confirming numerical calculations of the costs and benefits. 